\title{
Aerotecnica M\&S 100 Years Ago: Aircraft or Airship for the Future Air Transport?
}

\author{
Aldo Frediani $^{1} \cdot$ Vittorio Cipolla ${ }^{1} \cdot$ Sergio De Rosa ${ }^{2} \cdot$ Paolo Gasbarri $^{3}$
}

Accepted: 21 September 2021 / Published online: 4 October 2021

(c) AIDAA Associazione Italiana di Aeronautica e Astronautica 2021

\section{Dear Reader,}

This preface of issue n. 3, Volume 100, is dedicated to the English version of a paper published by Prof. Umberto Nobile in volume \#1, 1921, 100 years ago.

Umberto Nobile (1885-1978) distinguished himself above all in the design and construction of airships by creating new types of airships in Italy and abroad and he is universally known for the two North Pole flights, in 1926 and in 1928 when this last expedition ended dramatically.

Graduated in Engineering in 1908, he passed from the Administration of Public Works to that of War and, during the First World War, he was the director of the aeronautical construction plant; in the Air Force since its formation with the rank of lieutenant colonel, he reached that of General and, at the University of Naples he was Professor of Aircraft Design (1926-55). He conceived the first Italian parachute, promoted the construction of the first metal airplane in Italy and built the airships "Norge" and "Italy": with the first one, commanded by himself, he participated to an expedition promoted by R. Amundsen, crossing the unexplored arctic sea region between the pole and Alaska and flied over the North Pole in 1926. With the second one, commanded by himself again, in 1928 he made a long $(134 \mathrm{~h})$ exploration flight and flew over the pole a second time, but in the return, due to bad weather, the airship fell on the ice of the Svalbard. He saved himself with some companions but other companions died; his conduct was then the subject of controversy and an investigation committee made by political and military authorities, was very critical about the responsibilities of the commander (although he was firmly defended by Italian and foreign experts), leading to his resignment from the Air Force in 1929. From 1932 to 1936, he organized the construction of airships in the USSR. In 1945 he was readmitted to the Italian Air Force but his main interests were devoted to the teaching academical activity. In 1946, he was a member of the Italian Constituent Assembly.

In the paper presented below, Prof. Nobile takes a clear stand in the debate among supporters of the use of airships in civil air transport. In fact, by reading Verduzio's work [1] published in issue 1 of Volume 100, the reader can easily realize that the aeronautical technologies available in 1921 did not seem suitable for the development of aircraft capable of carrying high loads, as opposed to the airship. A different cultural stream, present in 1921 as well, argued the opposite argument that the future of mass air transport would be the prerogative of airplanes for their higher cruising speed and lower operating costs. The most authoritative scientific spokesman for this thesis was Enrico Pistolesi, a father of Aerodynamics (the reader can find a Paper by Pistolesi in the issue 2 of this Volume 100). In issue \#4 of Volume 100, we will report an article by Prof. Pistolesi in which he supports the thesis favourable to aircraft so that the reader of Volume 100 will have a complete overview of the debate, a century ago, related to the development of air transport scheduled for the rest of the twentieth century.

This issue \#3 is dedicated to the papers presented at the 2021 Pegasus Student Conference; the best papers presented were selected by a Scientific Committee chaired by Prof. Francesco Marulo and then reviewed according to the ATMS standards.
Vittorio Cipolla

vittorio.cipolla@unipi.it

1 Università Di Pisa, Pisa, Italy

2 Università Federico II Napoli, Naples, Italy

3 Università La Sapienza Roma, Rome, Italy 


\section{The Airplane and the Airship in Transport Services Umberto Nobile}

\section{Presented on April 22th, $1921^{1}$}

Anyone who wants to briefly express the essential characteristics for which the airship and the airplane differ each other would not hesitate to attribute great transport potential with limited speed to the airship and high speeds with limited transport potential to the airplane. Very different characteristics of the two means of air transport match distinct fields of practical applications, both civil and military. To admit that the 'lightest' and the "heaviest" of the air must compete with each other in the same field of action is a mistake, and an even more serious mistake is the assumption that one of the two means can break down the other: no longer arbitrary would it be, in the field of land or sea transport, to demand that between the passenger car and the train, between the ship and the dinghy, one of them should disappear. It is with this in mind that we are going to examine whether it is possible and appropriate to implement public services for the transport of persons by one and the other means of air locomotion. This examination must be carried out in relation to four capital points of the purchase: safety, regularity, comfort, cost of air travel.

\section{Safety of Air Transport}

In theory, in order to ensure the safety of a public transport service, everything should be perfect and perfectly working: fixed installations, route, equipment, staff, organization. In practice, perfection is unattainable, and so it happens that the defect of a material, of a mechanism, the inattention of personnel, the non-compliance with a regulatory rule, the intervention of external action can be the cause of a rail disaster or a shipwreck. The accident obeys to laws which cannot be specified, but no less real, indeed; thus, it happens that, for each transport enterprise, the disaster is repeated with a certain frequency depending on the type of plant, the degree of perfection of the materials, the personnel, the organization. It may be claimed that each transport has its own degree of safety. The question to be asked is therefore: in the current state of aeronautical technology, can an air service now offer a level of safety comparable to that of a rail, automotive or sea service carried out under normal conditions?

\footnotetext{
1 The technical part of the topic was carried out by the author, in a paper appeared in the Journal of Civil Engineering. No 5 of the year 1921, p. 270: "The future of air transport in public services (L'avvenire del trasporto aereo nei servizi pubblici).
}

\subsection{Safety in the Airplane}

In such a serious situation it is more necessary than ever to be honest.

The dynamic livelihood, this brilliant conquest of human ingenuity which, in its inflexible external forms and its intimate mechanism, is all the more brilliant and aesthetically suggestive than static livelihood, if it has rendered powerful services during the war, will not be equally useful to be exploited in civil uses, unless the serious risks, that seem congenital to it, are eliminated. Not to recognize immediately the very weak side of the technique of the heaviest of the air and to refrain, with general but inappropriate impatience, from wanting to try to activate commercial aviation prematurely with unsafe equipment, must be regarded as one of the main causes of the delay in the civil progress of the aircraft, since it distracts resources and energies, which would be much more profitably used to solve the fundamental and essential problem of safety.

Is the problem solvable?

At first sight it is undeniable that serious risks appear intimately and inevitably associated with dynamic livelihood. Staying in the air by virtue of a moving mechanism always implies the possibility of a fall or at least an involuntary descent into the ground when a failure in the pilot's mechanism or a manoeuvring error may occur.

However, we must declare that only small efforts have been dedicated to the solution of the problem, which is certainly not impossible, from the armistice onwards. The same psychology of war, which has attenuated the consideration of the value of human life, has done that energy and means have been preferably devoted to increasing the speed and autonomy of the device, rather than safety of the same.

However, we must be persuaded that commercial aviation, while it has not made any serious progress with the construction of devices similar to the current ones and capable of carrying a hundred people or more, will instead take a gigantic step on the day when the airplane will transport, perhaps, just one person, but with the safety that today is, unfortunately, still a myth. It is certainly a considerable step towards the achievement of the fragmentation of engine power, the adoption of safer operating engines, or the greater robustness of the structures, but a real huge progress will be made when, on the one hand, the intrinsic stability of the aircraft will be increased and, on the other hand, an important reserve of propulsion will be available in the normal flight, as it is already the case in the airship. That, in my view, is the fundamental problem. Only when it will be resolved, the airplane will be able to enter triumphantly in the field of public services, moving away from that of military and 
sporting applications, to which its activity would inevitably be limited if it were not. ${ }^{2}$

\subsection{Safety in the Airship}

For good luck, the same cannot be said of the airship. Airship transport can now be safe no less than sea transport.

In fact, let us quickly review the most serious accidents, from which a danger could arise: the failure of a part of the structure or of an engine, an error of manoeuvre, the depletion of stocks of petrol and oil, fog or an unexpected thunderstorm. The breakage of part of the airship's main structure, a failure of the manoeuvring or control devices, are extremely rare events in our airships, given the high strength of the single parts, which can very easily be achieved without excessively reducing the utilization. But even if such an accident occurs, the safety of passengers can never be compromised under any circumstances, because almost always the damage can be repaired by the personnel on board. At best, when the repair could not be carried out completely, a reduction of the cruise speed may be necessary. While, with regard to failures in the driving groups, it should be borne in mind that only a part of the available engines are used in the normal navigation of airships, keeping the others as a reserve; thus, it is immediately concluded that the failure of the engine-thruster groups can never compromise the safety of the journey, taking also in mind that in most cases it is perfectly possible to repair it on-board, without interrupting the flight. Similarly, an error of manoeuvre, (which would not in fact be conceived) during a normal navigation, cannot compromise the safety of the airship. From this point of view, safety is even better than on the railway, where the inattention of a driver or the error of a diverter can cause a rail disaster at any moment.

The most serious accident that can happen to the airship is certainly the exhaustion of stocks of petrol and oil, so that it would remain at the mercy of the wind. If you sail on land, there is no danger to passengers, because by manoeuvring as a free balloon you can land, although in very risky conditions for material. The case is more serious if it occurs in the sea even if the airship is equipped with giant float or, perhaps, lifeboats. But such an eventuality has been stated only to exclude it, because whatever journey you take, you must have on board, in addition to the petrol and oil necessary for normal navigation, an adequate reserve with which you pass

\footnotetext{
2 Editor's note: To the conditions of necessary progress, indicated by the Author for the safety of the flight in airplanes, we must add the other condition, no less essential, of the complete and systematic organization of ground-based services. Indeed, it can be said that at the present time the most urgent problem for the practical implementation of civil aviation is precisely a problem of organization on the ground: see in this regard on page 153 .
}

away in the event that you are dragged off the route, or, in any case, you are forced to extend the duration of the journey or to increase the speed of travel. Starting the journey with insufficient fuel supplies is just as inconceivable as it is for a ship. Fog and thunderstorm remain. As for the former, it may pose a real danger to the aircraft if it is forced to land, but never to the airship. At most, there may be a delay in landing, compromising regularity but not the safety of the operation. As for the second, it can even be said that, in the event of such a possibility, the airship is in conditions much better than those of a ship on which it (as indeed, and even more so, the aeroplane) has the advantage of greater speed (two to three times) and the possibility of rising to altitude. It goes without saying that, under such conditions, the airship will be able to escape the storm, even when the ship is obliged to undergo it. On purpose, we have not listed the danger of a fire as one of the possible accidents of the accident, because it does not exist, at least for well-conceived and well-built airships such as ours. However, we must stop briefly to consider this issue. Today there is much discussion of helium, and great importance is generally attached to its industrial production, since replacing hydrogen would eliminate any possibility of fire in airships. Now in principle there is no doubt that having an inert gas instead of a flammable one would be preferable. But, apart from the fact that it will most probably never be possible to produce helium in the considerable quantities required by aeronautics and at an affordable price, I believe that the moral advantage of replacing helium with hydrogen would not compensate enough for the sacrifice of ascensional force, with the exception, of course, of military airships which are the only ones really exposed during navigation to fire hazards when they are hit by enemy artillery. For civil airships I have spoken of moral advantage, because in reality with engines detached from the casing and agents in the open air, as it is the case in our own and German types, there is no danger of fire during navigation. It is true that precautions must be taken today to avoid the possibility of fire in hangars, but these precautions are so severe that it is certainly easier to see the fire on a hangar for airplanes than for airships.

\section{Regularity in Air Transport}

For a public regular transport service, this means essentially punctuality in arrivals and departures. From this point of view, we recognize, quite frankly, that the regularity of an air service is seriously subjected to the weather conditions, a subjection which translates into the fact that navigation is possible only on a certain number of days in the year. This number varies according to the characteristics of the aerial machine, according to the region where the service is developed and, also, to the duration of the journey. 
We have to say that this awe for the airship is currently much greater than for the airplane, although basically this does not come from the difficulty of keeping the air even with strong winds contrasting the flight, but although from the difficulty of getting in and out of the hangar with strong crosswinds. This is therefore a fundamental problem for the civil future of airships: to be able to leave and land even in very strong winds, without employing a disproportionate number of men for manoeuvring, and without over-stressing the structures of the airship. The problem, whether we want to solve itself with particular shapes or positioning of hangars (for example with adjustable hangars, as was already done in Germany), or by providing the current hangars of two windward wings that start from the end of the hangar walls and diverge towards the landing field in such a way as to allow the entry of the airship between those wings even keeping the airship axis normal to the hangar axis or, finally, whether we want to solve by special mechanical devices (rails, Crocco swivel platform), is essentially a question of plant expenditure. However, it should be noted at once that this increase in expenditure would be largely offset not only by the greater regularity of the service, but also by the reduction in labour expenditure, and above all by the increase in transport, so that, while taking the higher depreciation and interest on plant capital into account, this would result in a considerable reduction in the cost of the passenger-km, as we will demonstrate later with some figures.

Finally, there are those who think that this process will be resolved radically by the abolition of hangars, which would be replaced by special mooring systems both on land and on water. Without denying the importance of these systems, in the short term, both for supplies and for the loading and unloading of passengers, we consider it very unlikely that in the distant future we will give up, at least for the large airships, the comfortable and safe shelter which is the hangar, which can only effectively preserve the airship from the fuss of a thunderstorm and ensure a long life, while on the other hand it seems no less essential for the execution of works even of ordinary maintenance. However, whatever the further improvements in the constructive technique of aircraft or in fixed airport installations or, finally, in manoeuvring, it is undeniable that an air service could never achieve a degree of regularity comparable to that of rail or sea services, if we persist in wanting to extend the service throughout the year. Therefore, since 1918, in a first study on the cost of air transport with airships, I have affirmed the opportunity, I mean the need, to limit the service to the most favourable season, because only by having to ensure departures and arrivals on time at least 9 times out of 10 , it will be possible to accredit the service not only among tourists but also among businessmen. Less punctuality is acceptable for large trans-oceanic services only. This does not mean that the installations, the aircraft and the staff cannot be conveniently used even in the occasional good weather periods of the other seasons of the year; indeed, I think it is very appropriate, also for economic reasons, that where there is a considerable movement of foreigners, these periods should be used to manage tourist services, to which, by their very nature, occasionality does not harm, and which in any case do not have the need for regularity of a public service. This is all the more convenient in Italy, whereby a happy coincidence the tourist movement of foreigners occurs especially in the winter and spring months, which are precisely the least suitable for a regular air transport service.

\section{Comfort of Air Travel}

While safety and regularity are indispensable requirements for a public service, the comfort of travel is also of considerable practical importance. From this point of view, too, the superiority of the airship on the aircraft is evident. The large space and the large payload, which can be arranged in airships, make it possible to provide, without exceeding a convenient weight limit, all those comforts that are desirable, or at least necessary, on a long journey: comfortable seating, bed cabins, toilets, reading or detention room, kitchen, etc. In other words, even if in rudimentary form, and for a limited number of passengers, in the airship it will be possible to achieve most of the comforts that trains, or transatlantic ships offer today. Of course, obvious considerations of weight economy and requirements relating to the distribution of cargoes will impose tolerable restrictions, but on the other side the passenger will not suffer from seasickness. Being this the case, it should not seem excessive to say that the airship will be one of the most comfortable and enjoyable means of travel; perhaps the most comfortable, having on the ship the not insignificant advantage of the absence of seasickness, and on the railway the absence of shocks, vibrations, harassing noises. Of course, the same cannot happen for the current aircraft. The limitation of space and payload is reflected in a perhaps excessive limitation of comforts. Shocks, jolts and vibrations are very difficult to eliminate. In this respect, too, it seems to be necessary to conclude that the aircraft, as it is today, if it is suitable for sport and generally for the transport of people eager for pleasant emotions, is not suitable for the transport of normal passengers yet.

\section{Cost of Air Transport}

And, finally, we come to the last but very important question of the cost of air transport. First of all, it is curious to note that there is generally a widespread view that the cost of airship transport is greater than the cost of air transport, but this is precisely the opposite of what is in reality, 
when, of course, one imagines the airship applied to transports adapted to its particular characteristics. The arguments put forward in support of this opinion, without comforting them by means of numerical data are well known: hangar spending, manoeuvring staff spending, gas expenditure. Later, we shall demonstrate by an example how unfounded this opinion is, and how the expenditure mentioned by the hangar, the manoeuvring staff and the gas do not, in fact, influence the unit cost of transport too much. First of all, it should be borne in mind that in airships the consumption during flight (consumption of petrol and oil and engine depreciation) related to the unit of weight transported, are always considerably lower than in airplanes. The difference, which is already significant in small airplanes, is becoming increasingly strong as the size increases, so that (taking German constructions, for example) while in airplanes there is a maximum payload of $4.17 \mathrm{~kg}$ per hp, for airships this maximum is eight times greater: $33 \mathrm{~kg}$, per hp! There is no doubt, therefore, that the introduction of an airship service requires more capital than an airplane service, but to infer that this is also more expensive is wrong, just as it would be wrong to argue that the unit rail transport costs more than car transport, because it requires an enormously greater plant capital. The great power of transport, together with the undisputed fact that large installation and organization costs are required for a regular operation, clearly indicates that the airship is especially suitable for large-scale transport, with very heavy traffic. Similarly, the characteristics of the aircraft: small payloads, low autonomy, relatively low installation and organization costs, indicate that it is suitable for very limited traffic services. Adopting airplanes for large-speed missions, or airships for small transport, would, in general, increase the cost of transport. We conclude that also in economic terms the fields of action of these two different means of aerial locomotion appear to be well defined; a more stringent analogy leads to compare the airship with the train or with the ship, the airplane with the car or with the dinghy. The airship clearly demonstrates its aptitudes for a public service, the second is generally better suited to private services. Thus, we think it is very likely that in the future, although quite far away, while the major public air services will remain essentially entrusted to airships, the airplane, operating on public airfields, will mainly serve as a means of private transport. Probably it does not exclude the possibility that, in parallel to the main communications carried out with airships, it may be possible to complete the services with airplanes, especially for the private services, just as it happens today where, as a complement to the large rail network, there is a substantial network of public automobile services in Italy.

\subsection{The Cost of Air Transport in Comparison with the Cost of Other Systems}

An initial attempt to establish at least the order of the unit cost of transport (cost of pax-km or t-km) was made by myself, even before the war ended, in 1918. The study was limited to the airships but, since then, I have noticed that the cost of transport by plane should have to be, in general, considerably higher. In that study, proceeding on the basis of grossly approximate hypotheses, I tried to highlight that the cost is influenced not only by the aircraft's characteristics (cubage, maximum speed, normal speed) but also by the characteristics of the service (length of route, number of journeys, number of the days of navigation). I assumed as a constant the total number of $\mathrm{km}$ travelled in one year and, implicitly, I admitted that the airship was always used to the maximum. With this hypothesis, it became obvious that we should conclude that the unit cost of airship transport has to decrease as the cubage increases and, given the same cubage, it had to increase rapidly as the speed and route length increase. This, in fact, given the hypothesis, is equivalent to saying that the cost decreases as the intensity of traffic increases. From the results of the study we inferred, for example, that for a $30.000 \mathrm{~m} 3$ airship, capable of developing a maximum speed of $108 \mathrm{~km} / \mathrm{h}$, used for a normal speed of about $86 \mathrm{~km} / \mathrm{h}$ (at half of the available power), with a supply of petrol and oil equal to twice the requirements for normal navigation, the cost of the pax-kilometre (1 passenger $=100 \mathrm{~kg}$ ) was L. 0.49 on a route of $600 \mathrm{~km}$ and L. 0.69 on $1000 \mathrm{~km}$. We also glimpsed to be possible to reach minimum prices of 25 or 30 cents per pax-km in the case of a high traffic intensity, by adopting sufficiently large volumes in relation to the speed and route length. However, it should be noted that these forecasts were based on the assumption that the prices of raw materials had already fallen to their normal level, which I thought was just a bit higher than those of the pre-war period. Thus, for example, the cost of an airship was estimated at 70 lire per kilogram of dead weight, (today, for our airships, we are about 120 or 130 lire), a worker was supposed to earn on average L. 3600 per year (today, it is more than twice), the gas was assumed to cost $1 \mathrm{~L} / \mathrm{mc}$. (today it still costs $1.60 \mathrm{~L}$.) and finally the cost of petrol was estimated at $1 \mathrm{lira} / \mathrm{kg}$ (whereas today it is five times as much). It is therefore very likely that if those calculations are repeated based on current market prices, the unit cost of transport will almost triple. Considering, in addition, a bus service, which is the one with the greatest affinity for the air service, with not only the type of engine and the type of fuel in common with it, but also the absence 
of any expenditure relating to the route, it can be found that today the total expenditure for each $\mathrm{km}$ travelled (assuming a $50 \mathrm{~km}$ long line and two simple daily journeys) is L. 4,62. In fact:

\begin{tabular}{ll}
\hline $\begin{array}{l}\text { Interest, depreciation of fixed installations and rolling stock } \\
\text { renewal }\end{array}$ & L. 0.55 \\
Staff & L. 0.60 \\
Consumables & L. 3.30 \\
Insurance & L. 0.07 \\
Miscellaneous expenditure & L. 0.09 \\
Government surveillance & L. 0.01 \\
Total price per car-km & L. 4.62 \\
\hline
\end{tabular}

that is, a cost of about L. 0.57 per pax-kilometre if the car is assumed to occupied by 8 travellers on average.

Finally, it should be remembered that the price of maritime transport is about the same order of magnitude as the previous two. Therefore, we can conclude that air transport by airship costs two or three times more than other mechanical transport, unless we want to sacrifice the safety or the regularity of the operation by reducing fixed installations, or personnel, or speed, or, finally, reserves of petrol, oil and ballast. As already pointed out, a further reduction of airship transport cost will result from an increase of the cubature. However, it is to be expected that it will remain at least $50 \%$ higher than the cost of rail or sea transport. For the airplane, it will be at least twice more. But while conceding that sufficiently safe and regular air transport costs more than any other mechanical transports, the conclusion that it is not economically costly to implement it is just as arbitrary as asserting the superfluousness of the car because it costs more than the horse car.

The possibility of shorting the duration of a journey either with the higher speed of travel or by following the straight line between the two points to be connected, even though they are not at the same level or are separated by a very bumpy terrain, the absence of any installation and maintenance costs relating to the road are such characteristics as to put the air service in a position to compete advantageously with rail and ship or car. In particular, the airship remains on land the only mechanical vehicle capable of transporting as many passengers in a single journey as those carried by a train, without the need for a very expensive road system. It is sufficient to consider that today in Italy, for a normal gauge railway, the mere expense of the ballast and a rail of $36 \mathrm{~kg} / \mathrm{m}$, is not less than L. 400.000 per $\mathrm{km}$. Adding to this figure the expenditure for the construction of the road site, which is about half a million for flat land, is about a million per $\mathrm{km}$, half a billion for a 500-km-long railway. In front of these impressive figures, one remains convinced that in practice it sometimes occurs that air service is the only possible or convenient, on the economic side as well, to connect relatively distant locations, through deserted or very bumpy or impervious areas or with a traffic not heavy enough to justify the huge expenditure required to build an ordinary road or a rail route. Finally, we cannot stress enough the concept that even where there will be the presence of, together, air services and land or sea services, we can never talk of real competition between them. Such essentially different means of transport can only meet different commercial and industrial needs.

\subsection{The State and Private Initiative in Public Air Transport}

In the current state of Aeronautics, it would be harmful create illusions about the immediate contribution that private initiative could bring to the installation and operation of public transport services. The enormous capital needed, the complex, delicate and costly organization, the minor technical difficulties to be overcome in order to ensure a certain regularity of the service, the serious risks inherent in the management of such a new type of transport, the very high fares and, finally, the mistrust and scepticism of the public (which today are largely justified by the lack of safety of the aircraft and the poor navigability of the airship), are all difficulties against the emergence of private air transport initiatives.

If the State does not intervene to stimulate, to support and to coordinate private initiatives, or even possibly to replace them where conditions for their development do not exist yet, the civil aviation industry will inevitably be restricted in the field of sports applications or tourist services for many years to come. The latter ones are the only ones really free of risks, at least with airships, and highly profitable in countries where there is a strong touristic initiative. Now, the conquest of air presents -and there are not today those who do not recognize it - a political and military interest of such importance, that, in the languishing of private initiative, the State would be forced to increase the organization of its air force which, having to worry about its own particular needs, could only give a small contribution to solve the problems of such an essentially different nature as the civilian use of air transport. To encourage the development of civil aviation, to stimulate private initiative towards the management of wellordered transport services, is also equivalent to provide a solid basis for the country's possible air defence in the most economical way. This interest of the State in the creation of a civil aviation system should, in the first instance, be manifested not only by contributing by its own means to the solution of the most important technical problems relating to the civil use of the airplane and the airship, but also, perhaps, by directly managing, at an experimental level, public transport services, limiting them, for example, to a line of passengers with airships and a postal line with airplanes. It is, of course, 
far from our ideas that the State, which is a poor operator of industrial services in general, should assume a monopoly on air services. But it is essential that, in the present state of affairs, it should be the only one which really has the means and capacity to carry out a successful experiment on transport, the results of which, if favourable, would serve as a stimulus and a basis for private initiative, while on the other hand these results would provide valuable elements for determining how the State should support private industrial initiatives. This State contribution to private enterprises is likely to relate not only to service costs but also to plant costs. On the other hand, to relieve the concessionaire of the considerable costs inherent to the fixed plants, it will perhaps be necessary not only to stimulate private initiatives, but it will be also appropriate for general political and military considerations, which are likely to suggest that the State should be the only owner of airfields and landing runways, which should then be granted to private industry only in temporary use. As far as the operation is concerned, while the State should have no interference in the fixing of tariffs and in the treatment of personnel (with the exception of the obligation to provide insurance against shipping accidents), the annual government subsidy should be given in such a form and to an extent as to effectively encourage dealers to achieve not only the greatest safety and regularity that can be imposed, but also the higher traffic intensity. Therefore, it could consist of three distinct parts: the first proportional to the number of kilometres to be covered by heavy penalties for delays or suspensions in the service, even if caused by bad weather; the second proportional to the number of pax-km actually transported in the year; the third, finally, proportional to the degree of safety achieved, i.e. inversely proportional to the number of accidents which occurred for every hundred thousand kilometres travelled.

\subsection{Comparison of Airship and Airplane Transport Costs}

Let us consider an air service along a route length of $\mathrm{Km}$. 500 with a daily movement of 75 passengers in one direction and in the opposite one. A 35,000 mc airship is more than sufficient to transport 75 passengers on a non-stop route of $\mathrm{Km}$. 500. Suppose that the maximum speed is $120 \mathrm{~km} / \mathrm{h}$ and that normally only one third of the engine power is used, thus obtaining a running speed of $120 / \sqrt{3}=83.1 \mathrm{~km} / \mathrm{h}$ and an average effective driving speed (assumed an average wind of $20 \mathrm{~km} / \mathrm{h}$ ) of $78 \mathrm{~km} / \mathrm{h}$. The service, given the short duration of the trip, could be disengaged with a single airship. But we will prevent the purchase of 2 airships, both in order not to have excessive limitations in the choice of time, and because in all cases it is advisable to have a spare airship. We will normally assume that the service is disengaged by both, and exceptionally by only one of them, in the event of failure of the other. In order to make a fair prediction, we will assume that with the recovering and manoeuvring systems currently in use, given the length of the journey, there will be 150 flying days in a year. Then, in a year we make 300 trips, and will travel $300 \times 500=150,000 \mathrm{~km}$, carrying out a transport of $150,000 \times 75=11,250,000$ pax-km. For the same service with airplanes, in order to highlight their main characteristic, we will choose an aircraft that has a cruise speed of about $200 \mathrm{~km}$. per hour. Precisely, we assume to do the service with aircraft whose characteristics are the same as those of the seaplane Savoia S. 12, speed $214 \mathrm{~km} / \mathrm{h}$, power $150 \mathrm{HP}$, payload $725 \mathrm{~kg}$ (excluding pilot).

For an airplane, taking the greater number of flying days into account, it is fair to assume that the average wind is somewhat greater than for the airship, for example $25 \mathrm{~km} /$ hour. As an average effective speed of flight, we have $211.1 \mathrm{~km} /$ hour, then an average duration of $2 \mathrm{~h}$ and $22 \mathrm{~min}$ of the journey. In order to carry 150 passengers per day, it will be necessary to carry out $150 / 4 \cong 37$ flights and, assuming that any aircraft will normally make the round trip, we will have 18 aircraft in service, to which we will add a reserve of at least 7 more, reaching a total of 25 aircraft, to be purchased in order to satisfy the service. For an airplane, it is correct to consider that the number of flying days of the year is greater than the number for airships, so that assuming that there are 200 flying days, we have 7500 flights made in a year, travelling a total of $3,750,000 \mathrm{~km}$ and carrying out a transport of $15,000,000$ pax- $\mathrm{km}$. With regard to the costs of setting up and operating an air service, it must be recognized that the fluctuation and uncertainty of market prices make it very difficult to assess them, even if only approximately; but since we are particularly interested in establishing a comparison between the two types of transport, an even considerable error in the determination of one of the expenses will not have an excessive effect on the comparative final result. In all cases we warn that our figures are of value only by their order of magnitude. For airships, by calculating the costs of fixed installations, for two airships for 75 passengers and fixing an approximate figure for the working material, it may be established, at present prices and without demonstrations which will be given elsewhere, the following table of installation costs.

\begin{tabular}{ll}
\hline Terrain & L. $4,000,000$ \\
Stationary plants & L. $20,000,000$ \\
Construction site furniture & L. $2,000,000$ \\
Flying material & L. $6,000,000$ \\
Circulating material & L. $1,000,000$ \\
Total price & L. $33,000,000$ \\
\hline
\end{tabular}


Table 1 Summary of costs per passenger-kilometre

\begin{tabular}{|c|c|c|c|c|}
\hline \multirow[t]{2}{*}{ Costs per pax-km (L.) } & \multicolumn{3}{|l|}{ Service with } & \multirow{2}{*}{$\begin{array}{l}\text { Ratio of the } \\
\text { cost of the two } \\
\text { services }\end{array}$} \\
\hline & Airship & Airplan & & \\
\hline Interest and depreciation $\left\{\begin{array}{l}\text { fixed plant } \ldots \\
\text { flying material ... }\end{array}\right.$ & $\left.\begin{array}{l}0.238 \\
0.038\end{array}\right\} 0.276$ & $\begin{array}{l}0.099 \\
0.019\end{array}$ & 0.118 & 2.34 \\
\hline Replacement of flying material & 0.375 & 0.633 & & 0.59 \\
\hline Staff $\left\{\begin{array}{c}\text { of yards ... } \\
\text { in flight ... } \\
\text { for manouvers ... }\end{array}\right.$ & $\left.\begin{array}{c}0.106 \\
0.0402 \\
0.0040\end{array}\right\} 0.150$ & $\begin{array}{c}0.100 \\
0.050 \\
0\end{array}$ & 0.150 & 1.00 \\
\hline Maintenance $\left\{\begin{array}{c}\text { fixed plant and furnitures ... } \\
\text { flying material ... }\end{array}\right.$ & $\left.\begin{array}{l}0.062 \\
0.054\end{array}\right\} 0.116$ & $\left.\begin{array}{l}0.022 \\
0.027\end{array}\right\}$ & 0.049 & 2.37 \\
\hline Navigation consumption & 0.261 & 0.667 & & 0.39 \\
\hline SUB-TOTAL & 1.178 & 1.617 & & 0.73 \\
\hline Overheads and traveller insurance & 0.182 & 0.243 & & \\
\hline TOTAL & 1.360 & 1.860 & & 0.73 \\
\hline whose $\left\{\begin{array}{l}\text { related to fixed plants } \ldots \\
\text { related to flying materials ... }\end{array}\right.$ & $\begin{array}{r}0.406 \\
0.954\end{array}$ & $\begin{array}{r}0.221 \\
1.639\end{array}$ & & $\begin{array}{l}1.84 \\
0.58\end{array}$ \\
\hline Cost per kilometre (L.) & 102 & 7.4 & & 13.7 \\
\hline
\end{tabular}

For the service by airplanes, calculating the costs for fixed installations, for 25 airplanes with 4 passengers and fixing the same figure for the working material, this new table may be fixed at present prices for plant costs:

\begin{tabular}{ll}
\hline Terrain & L. $4,000,000$ \\
Stationary plants & L. $8,000,000$ \\
Construction site furniture & L. $2,000,000$ \\
Flying material & L. $4,000,000$ \\
Circulating material & L. $1,000,000$ \\
Total price & L. $19,000,000$
\end{tabular}

The ratio of the installation costs of the two services with aircraft and airships is about 0.6. In general thesis, plant expenditure is a function of the type of equipment, the speed of flying machine, the route speed and the number of transported people and, of course, increases as the latter three elements increase.

However, it is interesting to note that when the type and size of the device and the speed of travel are fixed, and the route length is considered variable according to the inverse of the number of passengers transported, the total cost of installation may, within certain values of the route lengths and with the same conditions as far as the consumable materials, be considered independent of the length of the journey.

However, this does not necessarily mean that expenditure on interest and depreciation relating to the pax-km should increase with the distance (and thus with the decrease of the passengers) because, in many cases, it can happen precisely the opposite. To realize this, it should be considered that the number of km-pax transported with a given device at a given speed is proportional to the product of two quantities, the sum of them is a constant (payload of the device). The best condition is therefore when the payload is divided equally between the weight of passengers and the weight of the supplies of petrol and oil. In the case of the airship, for example, if the length of the route increases from 500 to $1000 \mathrm{~km}$., the plant capital approximately remains unchanged, while the number of passengers is reduced from 75 to $(7500-3138) / 100=38.6$ and therefore the number of pax-km increases from 37,500 to 38,600 , i.e. the unit expenditure on interest and depreciation decreases. The previous observation made applies, as mentioned before, up to a certain length of the route, beyond which the number of annual journeys necessarily decreases and, with it, the total number of passengers per year. Finally, we would point out that plant expenditure undoubtedly increases with the potential of the plant itself, i.e. with the number of pax-km per

Table 2 Breakdown of costs

\begin{tabular}{llll}
\hline Cost category & \multicolumn{2}{l}{ Service with } \\
\cline { 3 - 4 } \cline { 3 - 3 } & Airship & Airplane \\
\hline 1 & Interest and depreciation & 0.20 & 0.06 \\
2 & Replacement of flying material & 0.27 & 0.34 \\
3 & Staff cost & 0.13 & 0.08 \\
4 & Maintenance cost & 0.08 & 0.03 \\
5 & Navigation consumption & 0.19 & 0.36 \\
6 & Overheads ................. & 0.13 & 0.13 \\
& & 1.00 & 1.00 \\
\hline
\end{tabular}


year. It is therefore appropriate to report the expenditure to the pax-km. In our case you have:

\begin{tabular}{ll}
\hline Airship service & L. 2.93 per pax-km \\
Airplane service & L. 1.26 per pax-km \\
\hline
\end{tabular}

For the annual operating expenditure, as a conclusion of the calculations which we omit here for the sake of brevity, we can fix these two other Tables 1 and 2:

From these two tables, it can be seen that expenditure on interest, amortizing and maintenance of fixed installations and on personnel in the building's accounts for a total of $33.4 \%$ of total expenditure on operations in the case of airships and only $13.6 \%$ in the case of airplanes. It is now clear, for obvious reasons, that the expenditure referred to above (relating to the $\mathrm{km}$ pax) are rapidly decreasing as traffic increases, whether this increase is incurred, where possible, by increasing the route lengths, whether the number of the devises is increased or, finally, their sizes are increased. It follows immediately that, when the traffic increases, the economic advantage of the airship on the plane increases more and more. As a special case, if we assume to increase the route length or the number of the flying machines leaving their size unchanged, the ratio of the total operating expenses/(pax-km) tends to the ratio, per pax-Km, of the total expenditure which may be considered to be in proportion to the journeys, i.e. those relating to navigational consumption, the renewal of rolling stock and personnel on board.

In our case, the total amount of these expenses, with an allowance of $15 \%$ for general expenses and passenger insurance, is 0.931 for the airship and L. 1,606 for the airplane. The ratio is 0.58 . The size of the vehicle generally results into a reduction of the operating costs when, of course, a well-used is supposed. This is due to the fact that the expenditure for personnel on board, consumption and renewal, per pax-km, is falling down, although not indefinitely (for airships the limit is given by the cubage, that we call economic). ${ }^{3}$

This consideration, together with the other one which, while undoubtedly the airship can increase its dimensions to very high limits, this possibility appears to be very problematic for the aircraft, leading to the consequence that the economic advantage of the airship on the aircraft, measured by the ratio of the transport costs of the pax- Km, is likely to exceed even the limit indicated above. Of course, the opposite is true in the case of the reduction in traffic: expenditures on fixed installations and site personnel is increasingly important in determining the unit cost of transport: the advantage of the airship on the aircraft initially diminishes and then ends, up to become negative.

We have mentioned elsewhere that the expense of the hangar does not weigh heavily on the cost of airship transport, when, of course, the traffic is sufficiently heavy. Thus, in our example, the expense for the plant is eight million, and the relative annual expenditure of $13 \%$ of that amount, i.e. L. 1,040,000, corresponds to L. 0.093 per pax-Km, i.e. only $6.6 \%$ of total expenditure. This also justifies our observation that it is not appropriate to skimp on this expenditure, and that it may sometimes be appropriate to bear even more costs by equipping, for example, the hangar of windward wings or a mechanical device for the entry and exit manoeuvre, when these installations result in an increase in the number of annual flying days. Thus, for example, let we assume that for these subsidiary plants we need a higher expenditure of 2 million and, therefore, and operating personnel expenditure of L. 260,000 per annum; consequently, the expenses relating to fixed installations (interest, amortize, maintenance) and site personnel increase in absolute value from 5,090,000 to L. 5,376,000 but, referring to the pax-km, the expenses decrease from L. 0.449 to L. 0.358 , not to mention the indirect advantages of the increased regularity of the service.

\section{References}

1. Frediani, A., et al.: Aerotecnica M\&S: 100 years behind to explore new horizons. Aerotec. Missili Spaz. 100, 1-13 (2021). https:// doi.org/10.1007/s42496-021-00076-4

Publisher's Note Springer Nature remains neutral with regard to jurisdictional claims in published maps and institutional affiliations.

\footnotetext{
${ }^{3}$ Editor's note: On the subject of economic cubage, see "The use of airships in passenger transport. - Investigation on the maximum limits of payload, station, altitude and speed" Giornale del Genio Civile, January 1921, p. 3-41. This study completes the similar previous study by Col. A. G. Crocco "Study on the weight of the dead load of airships and on the number of transportable passengers" published on Rendiconti dell'Istituto Sperimentale Aeronautico, year VIII $2^{\text {nd }}$ series, n. 2, September 1920.
} 